only large, relatively pristine wilderness areas are in the tropics.

'The data collected here - particularly the newlyassembled information on human disturbance to the planet - convey a critical message' says Conservation International's President Russell A. Mittermeier. 'Maintaining our remaining tropical ecosystems and their wealth of plant and animal species is one of today's most important conservation challenges.'

Because every species-extinction represents an irreversible loss, precisely locating areas of high biological diversity is critical. Four of the maplets in Biodiversity at Risk depict the relative numbers of species of birds, mammals, reptiles, and amphibians, by country. Chosen because they are the main animal groups for which pertinent information on distribution is available, these species reflect overall patterns of diversity - and dramatically illustrate that the highest concentration of biodiversity lies in key areas in certain tropical nations. But comparing biodiversity distribution maps with maps displaying data on conservation capacity, reveals a serious gap in human resources, namely that of the countries which are richest in species being the least technically prepared to protect them.

Measured in terms of natural science students and herbarium specimens - the biologists and stored plant materials that are needed to assess a region's biodiversity - two of the maps in Biodiversity at Risk show that developing countries in Africa, Asia, and Latin America, fall far short of industrialized nations. As an example, one of the maps shows that Bolivia — which ranks high on all four biodiversity maplets - has only a handful of postsecondary-school natural science students. In 1990, a Conservation International-sponsored Rapid Assessment Program (RAP) team uncovered an extraordinary level of biodiversity in an unexplored Bolivian rain-forest near the Peruvian border. Officials immediately recommended that the area, known as Alto Madidi, be protected by the government. It had been overlooked before because Bolivia's few, overworked field biologists had not had an opportunity to survey the area.

Another example is Madagascar, considered one of the world's top three endangered 'hotspots'. Although Madagascar has an estimated 8,000 to 10,000 different plant species - about $80 \%$ of them found nowhere else on Earth - it has fewer than 10 herbarium specimens for each species in the country. By contrast Great Britain, which has only a fraction of the number of plant species possessed by Madagascar, has an average of 1,000 or more dried herbarium specimens per species.

'The first step in protecting biodiversity is scientific research: studying [individual ecosystems and their aggregations into wider ecocomplexes as well as] their species - and identifying threats to their survival - is the foundation of conservation,' says President Mittermeier. 'What we need is a global conservation corps, with each country making a national priority of training conservationists and providing the technology and resources [that are] needed to study and protect its own biological wealth.'

Conservation International's strategy of ecosystem and ecocomplex conservation includes a major focus on cultivating local conservation capacity in countries that are home to the planet's greatest and most threatened biodiversity. The organization works to build conservation capacity in developing countries through financial and technical support to local communities, private concerns, and government agencies.

LAURA TANGLEY
Conservation International
1015 18th Street NW, Suite 1000
Washington
DC 20036, USA.

LAURA TANGLEY 101518 th Street NW, Suite 1000 DC $20036, U S A$.

\title{
Nature Conservation in Central and Eastern Europe: the Time for Change and Hope*
}

$T^{\text {he }}$ The fall of authoritarian political regimes in central and eastern Europe has introduced new uncertainties but also new hopes for Nature conservation on the continent. The mismanagement of natural resources is a common feature of dictatorial forms of government, where public opinion cannot influence development or conservation policies. Thus vast areas have been severely polluted, cities have grown tremendous and ugly, rivers have been transformed into open-air sewers, and intensive agriculture and land consolidation have flattened and simplified otherwise colourful and diverse rural landscapes.

The results of eastern Europe's ageing industry, and the lack of the most elementary pollution-control standards, have been widely publicized. Yet the irrationality of authoritarian policies has also left vast parts of the territories of those states virtually untouched in the past 40 years, receiving little or no exploitation. This means that, not far from heavily polluted areas, we still find almost pristine mountains and well-preserved forests with interesting animal species, such as the Brown Bear (Ursus arctos), the Wolf (Canis lupus), and the Lynx (Lynx

* Based on the account in Naturopa-Newsletter, Special Issue on the Bern Convention, Nr 3, 1992. - Ed. $l y n x)$, which are practically absent from western Europe. The Russian steppes, the Balkans, the Carpathian mountains, and the River Danube, all contain ecosystems and wider ecocomplexes of the highest importance for the conservation of Europe's natural values. It is a shared responsibility of all Europeans to preserve their rich heritage.

\section{Coming Years Critical}

The next years will be critical for the future of wildlife in central and eastern Europe. There will be in this region a very logical trend towards economic development, which may affect wilderness areas drastically. As the economic situation improves, new roads, dams, and industries, will be built, tourism will develop in rural areas, and hunting, agriculture, and forestry, will undergo deep changes. The real challenge will be to control and direct 'market forces' so that they respect the beauty and interest of the natural areas - a task which has to be contemplated on a pan-European scale. Thus the answer lies in wise sustained development and international cooperation. These are the ideas behind the Convention on the Conservation of European Wildlife and Natural Habitats, better known as the 'Bern Convention'. 
Ten years ago, in June 1982, the Convention, which had been signed in September 1979, came into force. This Convention is quite an original treaty, as it does not just concern one aspect only of Nature conservation, but tries to cover them all, setting the basis of a real strategy for the conservation of Nature in the signatory states. It contains very strict obligations concerning the protection of threatened species as well as their habitats, but it does not stop there. The underlying principles of the Convention are that all development activities and policies need to have regard for the conservation of wild flora and fauna. Special attention is given in the Convention to endangered, endemic, and migratory, species. The Parties to the Convention make a formal undertaking to avoid or minimize any deterioration of the areas in which such species live, as well as to conserve endangered natural habitats.

During the $1980 \mathrm{~s}, 19$ out of the 21 states which were members of the Council of Europe at that time ratified the Convention. The Convention was also acceded to by two African states (Burkina Faso and Senegal), and by the European Economic Community. All these states adapted their national legislation to the provisions of the Convention, thus helping to harmonize their different approaches to the common goals and strategies set up by the Convention.

A new and particularly interesting example of legislation derived from the Convention is the so-called 'Habitats Directive', which has recently been adopted by the EEC. In this Directive the obligations set out in the Convention are transformed - and, even better, enlarged and improved - into Community legislation. Although the Habitats Directive affects at present only the 12 member States of the European Communities, it will concern other states in the future - such as those in EFTA - which join the Communities.

\section{The Convention and the States of Central and Eastern Europe}

The 1990s have already been, and will certainly continue to be, dramatically different from the $1980 \mathrm{~s}$. This is also true for Nature conservation policies, ideas, and action. The wind of freedom has brought new member States into the Council of Europe and to the Bern Convention. Bulgaria, Czechoslovakia, Hungary, and Poland, are already members of the Council of Europe. Bulgaria and Hungary joined the Bern Convention even before they became member States, as the Convention is not restricted to the member States of the Council of Europe.

In March 1992 the Committee of Ministers of the Council of Europe invited Albania, Estonia, Latvia, Lithuania, and Romania, to join the Convention. All these states, together with the European Republics of the former Soviet Union, are expected to accede in the years to come. At present the Council of Europe has 27 member States and the Bern Convention has 25 Contracting Parties; but the situation changes so quickly that this statement may already be outdated by the time this article is published!

In any case, the vocation of the Bern Convention is to cover the entire territory of Europe, and also North Africa, as the biological links of both continents are very strong and the conservation problems of North Africa differ little from those of southern Europe. In such a vast territory, extending from the Atlantic Ocean to the Ural Mountains and from the Arctic Sea to the Sahara Desert, the Bern Convention should ensure that more than 40 states adopt a similar approach to Nature conservation and have, for instance, the same list of protected species - whether they are naturally present in their territories or not.

The main priority of the Convention is now its development and reinforcement in central and eastern Europe. This will mean, for instance, that the list of species protected in Appendices I, II, and III, of the Convention will have to be adapted. Activities which interest those states will have to be added to the Convention's work, such as the management of big populations of carnivores (Brown Bear, Lynx, and others). In most of the Parties to the Convention in western Europe, big carnivores such as the Brown Bear receive full protection, because they are restricted to remote areas to which usually only small populations are confined. This is certainly not the case for Romania, Russia, or Belarus, where the emphasis will now be on developing hunting strategies that permit both a reasonable culling (likely to satisfy local hunters or to attract much-needed foreign currency) and the necessary long-term preservation of healthy populations.

The principles established in Article 7 of the Bern Convention regarding the exploitation of wild fauna can, for instance, set useful guidelines for states of central and eastern Europe. That article contemplates the regulation of the exploitation of species listed in Appendix III of the Convention and prohibits exploitation wherever (or whenever) the population of a species does not maintain a satisfactory level. It also requires, in certain cases, due regulation of the sale or transport of living and dead wild animals. The Romanian population of Brown Bear, for instance, hit its lowest point in 1950, with less than 1,000 individuals remaining. Now it stands at about 5,000 Bears. It would be regrettable if a new hunting policy did not succeed in maintaining some sustained exploitation of the present population, as the principles set out in the Bern Convention suggest.

\section{Expectations from States Joining the Bern Convention}

Most states of central and eastern Europe seem to be eager now to join the Convention, which will allow them to participate fully in this international treaty and in the cooperative framework that it offers. One must not forget, however, that when states become Parties to treaties they freely accept the obligations contained in those treaties. This means that the new European democracies will most likely have to change their Nature conservation laws to adapt them to the Bern Convention, as was done by western European countries in the 1980s and will have to be done by those signing the Convention in the 1990s.

It is likely that the new legislation will be - for some states at least - quite an important improvement, as it will develop some interesting aspects of the Convention (on invertebrate protection, on reintroductions, on introduction of exotic species, and on habitat protection) which are now treated very differently. Some species that were not protected before will have to be protected, and substantial changes will have to be made in the protection of the habitats of some threatened species.

It is likely that the convention will prove dynamic in the way protected areas are managed. Some states already have good national networks of protected areas, but they need to be better staffed and financed than at present. 
Reserves need to be better integrated in their social and economic environment than is currently the case, and act, as far as proves feasible, as bases for the development of surrounding territories. The challenge is indeed great!

\section{How the Convention Works}

The Council of Europe, with headquarters in Strasbourg, acts as Secretariat of the Bern Convention. It serves a 'Standing Committee' which meets every year in December to decide on the activities and subjects on which the Convention will concentrate. This Committee amends the Appendices of the Convention and enlarges its scope by way of recommendations and action programmes. Cooperation of all the states participating in the Convention is fundamental to making progress in the conservation issues dealt with, as many environmental problems can only be solved at the international level.

Much of the Bern Convention's work in recent years has been devoted to threatened species, with particular emphasis on carnivores, plants, amphibians, reptiles, and invertebrates. Many nongovernmental organizations participate very actively in the work of the Standing Committee, and play a fundamental role in developing the Convention. Not only do they bring forward ideas but also 'hot cases' in which the actions of one government risk to be in disagreement with the Convention. The Committee opens files, often sends observers to those 'hotspots', and recommends specific action to be taken by governments. The spirit reigning in Strasbourg is always of fruitful cooperation among states. To complete this aspect of European unity it is fundamental that the new democracies join the Convention.

ELADIO FERNANDEZ-GALIANO
Secretariat of the Bern Convention
Centre Naturopa
Boite postale 431 R6
F-67006 Strasbourg Cedex
France.

\section{Unusually Low Ozone Levels Over Antarctica}

A substantial decrease in the ozone layer over Antarctica was announced in September 1992 by the World Meteorological Organization (WMO) via its bulletins on the state of the ozone layer disseminated through its Global Telecommunications System (GTS).

Based on the latest reports from Antarctica, WMO states that ozone levels are now from 30 to $35 \%$ lower than were the pre-ozone-hole-discovery averages during 1957-77. The depletion is particularly affecting the North-west and parts of the North-east sectors of Antarctica. This unusually early decline started during the last days of August and in early September, spreading over the South Pole and practically everywhere polewards from $70 \%$ South during the second week of September 1992. Some stations such as Marambio, Faradey, and Syowa, have registered the lowest daily values for these months of well below 200 ozone units $(\mathrm{m}$ atm $\mathrm{cm}$ ).

According to Dr Rumen D. Bojkov, Chief of WMO's Environment Division in Geneva, the air enclosed in the polar stratospheric vortex is extremely cold, reaching temperatures of below minus 85 degrees Celsius in the lower stratosphere. 'This condition is a prerequisite for extensive ozone destruction, once the Sun appears in the Antarctic', Dr Bojkov said. Based on these findings, scientists expect a prolonged 'ozone-hole period' to last until the disintegration of the polar stratospheric vortex which normally occurs each year during the month of November.

The ozone layer screens out the Sun's harmful ultraviolet radiation, which can cause skin cancer, eye cataracts, and a suspected weakening of some human immune systems. Besides the hazards to human health, continued depletion of the ozone layer could have some negative effects on crop yields and aquatic life, as well as in changing the radiative regime of the Earth's atmosphere, that could be expressed by marked cooling in the lower stratosphere.

Since the first reporting of the Antarctic-spring ozone decline in the late $1970 \mathrm{~s}$, the total ozone has been gradually declining each year from the end of August, reaching its lowest ozone values annually during the first part of October, and recovering to normal values in late November. WMO's analysis of the ozone layer for the past ten years shows that the total ozone deficiency in late August this year has been on average approximately $20 \%$ below its pre-ozone-hole-discovery values.

Measures are being undertaken to eliminate the production and use of chlorofluorocarbons (CFCs), which are the main causes of the stratospheric ozone depletion, in accordance with decisions formulated by the Montreal Protocol. A meeting of the Parties to the Protocol is being organized by UNEP in November 1992, to discuss strengthening of Protocol measures against substances that deplete the ozone layer.

The new findings are based on provisional data received by WMO from its member governments' operating Global Atmospheric Watch stations and satellites around the world. These include the Global Ozone Observing System stations in Antarctica operated by Argentina/Finland, Germany, Japan, New Zealand, United Kingdom, and United States, as well as on satellite data provided by the US's National Aeronautics and Space Administration (NASA) and National Oceanic and Atmospheric Administration (NOAA).

Updated stratospheric ozone values will be available shortly from the WMO World Ozone Data Centre, based in Toronto, Canada. For further information please contact the undersigned:

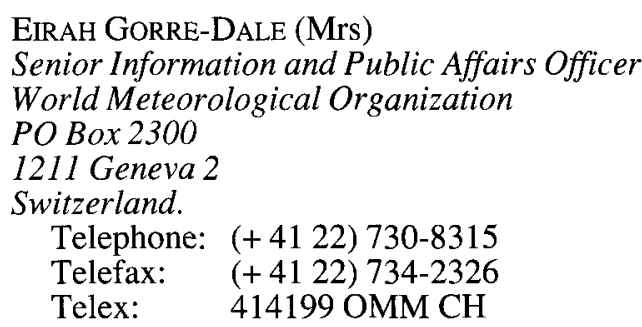

